\title{
Possíveis relações entre percepções de violência dos alunos, clima escolar e eficácia coletiva
}

Marcela Brandão Cunha'

\section{Resumo}

Este artigo busca verificar a relação entre clima escolar e percepções de violência dos alunos, no que diz respeito ao testemunho e ao envolvimento em contextos de violência. 0 referencial teórico se baseia na articulação entre duas teorias de áreas distintas: clima escolar e eficácia coletiva, sendo a primeira originária de estudos a respeito da eficácia escolar e efeito-escola e a segunda desenvolvida no âmbito da sociologia urbana. Essa relação foi pensada ao serem identificadas convergências consistentes entre as referidas perspectivas. No que se refere à metodologia, foram analisados dados quantitativos provenientes de um survey realizado no Rio de Janeiro sobre juventude e violência, fruto de uma parceria entre pesquisadores de três universidades: Universidade Federal do Rio de Janeiro (UFRJ), Universidade Estadual do Rio de Janeiro (UERJ) e Universidade Cândido Mendes (UCAM). Resultados preliminares mostram associação negativa entre indicadores de clima escolar e de percepções de violência dentro da escola. Isso sugere que, em escolas cujos alunos relatam um maior número de ocorrências de violência, o clima escolar é avaliado negativamente por eles. Além dessa convergência verificada com a hipótese do estudo, outros dados apontam relações entre percepções de violência dentro e fora da escola e associação entre percepções a respeito da existência de drogas e de violência no espaço escolar. Contudo, em relação aos referidos resultados, vale enfatizar o caráter exploratório das análises.

\section{Palavras-chave}

Clima escolar - Eficácia coletiva - Percepções de violência. 


\title{
Possible relationships between students' perceptions of violence, school climate, and collective efficacy
}

Marcela Brandão Cunha'

\begin{abstract}
This article aims to verify the relationships between school climate and students' perceptions of violence, with regard to witnessing and involvement in violent contexts. The theoretical framework is based on a relationship between two theories from distinct areas: school climate and collective efficacy. The first originated from studies on school effectiveness and school effect; the second was developed in the context of urban sociology. This association was considered because of convergences identified between those two theories. Quantitative data were analyzed from a survey conducted in Rio de Janeiro concerning youth and violence. This resulted from a partnership between researchers from three universities: Universida de Federal do Rio de Janeiro (UFRJ), Universidade Estadual do Rio de Janeiro (UERJ), and Universidade Cândido Mendes (UCAM). Preliminary results showed a negative association between indicators of school climate and perceptions of violence inside the school. These results suggest that in schools where students reported a greater number of violent occurrences, there also exists a school climate that students evaluate negatively. Besides the verification of this convergence by our study's results, other data suggest relationships between perceptions of violence within and outside the school and perceptions of the existence of drugs and violence at school.
\end{abstract}

\section{Keywords}

School climate - Collective efficacy - Perceptions of violence.

I- Pontifícia Universidade Católica do Rio 


\section{Introdução}

Este artigo investiga a relação entre clima escolar e percepções de violência dos alunos, tratando por percepções os relatos dos estudantes a respeito de testemunhos e envolvimento em contextos de violência. Para isso, foram analisados dados quantitativos provenientes de um survey cujo tema foi juventude e violência, realizado no Rio de Janeiro, através de um projeto de pesquisa que contou com a participação de pesquisadores de diferentes universidades: Universidade Federal do Rio de Janeiro (UFRJ), Universidade Estadual do Rio de Janeiro (UERJ) e Universidade Cândido Mendes (UCAM). Entre outros objetivos, o referido projeto tinha como enfoque as percepções de violência de jovens, em processo de escolarização, matriculados em escolas públicas do município do Rio de Janeiro.

Além da relação entre clima escolar e as variáveis de percepção de violência na escola, será verificada neste trabalho a relação entre clima escolar e a existência de drogas e bebidas alcoólicas na instituição. Muitos autores abordam a coexistência de contextos de violência e consumo e/ou venda de drogas, apesar desses elementos não estarem necessariamente relacionados.

0 referencial teórico é abordado com ênfase na identifıcação de convergências entre duas teorias de campos distintos, denominadas clima escolar e eficácia coletiva. A primeira é proveniente de estudos a respeito da eficácia escolar e efeito-escola; já a segunda insere-se no âmbito da sociologia urbana. As duas seções subsequentes tratam do contexto que propiciou o surgimento de cada um dos referidos modelos teóricos e a relevância desses para as respectivas áreas de estudo. Na sequência, as duas teorias referidas são articuladas com o objetivo de identificar os principais pontos convergentes. Por fim, são destacados os esclarecimentos acerca dos procedimentos metodológicos adotados, a análise dos dados e as considerações finais deste estudo.

\section{Eficácia coletiva}

A primeira metade do século XX nos Estados Unidos é caracterizada pela popularidade de teorias criminológicas denominadas individualistas, as quais associavam características individuais a possiveis causas de crimes. Entretanto, essas foram criticadas por ignorarem o contexto de crescentes mudanças sociais resultantes dos processos de industrialização e urbanização e do crescimento populacional. Assim como abordam Cullen e Agnew (2011), a cidade de Chicago é um exemplo de tais transformações, na medida em que houve um aumento populacional sem precedentes, principalmente devido à migração de indivíduos atraídos por empregos nas fábricas. Tais trabalhadores, de diferentes grupos étnicos, viviam em sua maioria em bairros pobres e com condições precárias de moradia. De acordo com os mesmos autores, é nesse contexto que estudiosos da Universidade de Chicago, com concepções opostas às teorias individualistas, começaram a investigar justamente as características de tais bairros, já que atribuíam importância a fatores contextuais e não aos individuais.

0 trabalho de Shaw e McKay (1942, apud SILVA, 2004) é bastante influenciado pelos autores da Universidade de Chicago, sendo um dos pioneiros entre os que tratam da distribuição espacial de crimes, tendo a cidade como unidade de análise. Considerado um dos mais significativos, o referido estudo apontou indicadores sociais de regiões específicas como altamente relacionados às taxas de crimes com autoria de jovens. Tais indicadores foram também explorados em estudos posteriores. São eles: heterogeneidade étnica, mobilidade residencial e privação econômica.

De acordo com essa perspectiva: a heterogeneidade étnica atuaria como uma barreira, impedindo a existência de valores compartilhados e dificultando a comunicação e interação entre os moradores de determinada comunidade; a mobilidade residencial abalaria as redes comunitárias de relações sociais; e a privação econômica acarretaria dificuldades 
para a resolução de problemas da comunidade. Tais fatores associados resultariam no que se denomina "desorganização social” (SILVA, 2004), que, em linhas gerais, corresponde à falta de êxito dos moradores de determinada localidade em exercerem um controle social sobre a mesma. Esse controle atuaria principalmente na vigilância e supervisão das atitudes e ações dos jovens nos locais, já que, para os referidos autores, a criminalidade e crimes com autoria de jovens consistiriam em fenômenos de grupo resultantes de frágeis e ineficientes meios de supervisão e controle. A presença ou ausência de supervisão encontra-se, em geral, relacionada ao grau de coesão da comunidade, fator associado à eficácia da autorregulação. Portanto, considerando os fatores estruturais das comunidades, a organização e a desorganização social estariam associadas à maior ou menor capacidade de articulação entre moradores com o intuito de inibir a ocorrência de crimes.

A partir da década de 1970, os estudos da escola de Chicago, referidos nos parágrafos anteriores, reconquistaram visibilidade entre as teorias criminológicas. Fortemente influenciado por tais pesquisas, o trabalho de Sampson; Raudenbush e Earls (1997) introduz o conceito de efıcácia coletiva, defınida como coesão social entre vizinhos e a articulação desses por meio de ações voltadas ao que é de interesse comunitário. Portanto, eficácia coletiva pode ser defınida como uma espécie de união entre coesão social e controle social informal. De acordo com os autores, por coesão social, entende-se a possibilidade de estabelecer regras coletivamente e de comum acordo, e, por controle social informal, entende-se a capacidade que um grupo possui de regular as ações de seus integrantes, de acordo com princípios compartilhados entre os mesmos.

A fim de investigar a relação entre eficácia coletiva de determinadas comunidades e as taxas de crimes ocorridos nas mesmas, Sampson e seus colaboradores primeiramente verificaram a relação entre fatores estruturais da vizinhança, os mesmos tratados no estudo de Shaw e McKay - pobreza concentrada, taxa elevada de imigrantes e de estabilidade residencial - e a eficácia coletiva. A partir dessa análise, verificou-se que 70\% da variação de eficácia coletiva são explicados por tais fatores. Posteriormente, constatou-se que a existência de eficácia coletiva na vizinhança se encontrava negativamente associada à violência. Nos resultados desse estudo, a eficácia coletiva é apontada como mediadora conceitual da relação entre os fatores estruturais mencionados e o contexto de criminalidade de uma determinada comunidade. Portanto, de acordo com o autor, o enfoque na eficácia coletiva não deve criar margem para que se negligenciem as desigualdades estruturais existentes entre bairros e comunidades, tais como fatores de ordem socioeconômica.

Há, em relação ao âmbito escolar, estudos que investigam processos similares ao abordado nesta seção. Trata-se do clima escolar, o qual diz respeito aos processos internos à escola. Tais pesquisas investigam suas possíveis implicações para o desempenho escolar e aspectos comportamentais dos alunos.

\section{Processos intraescolares e clima escolar}

Estudos realizados entre o final da década de 1950 e a década de 1970 adotavam uma perspectiva macrossocial, ao investigarem principalmente os resultados de sistemas educacionais, medidos através do rendimento escolar dos alunos. A principal explicação desses resultados se baseava em indicadores individuais dos estudantes, tais como aspectos socioeconômicos e culturais. Os efeitos identificados no nível das escolas eram discretos. Apenas posteriormente se passou a considerar a instituição escolar como importante unidade de análise e seus processos internos como relevantes objetos de investigação. Nesse contexto, destacam-se principalmente pesquisas realizadas por norte-americanos e ingleses. 
Estudos realizados a partir da década de 1970 passam a enfatizar a dinâmica interna das escolas para o entendimento de seus resultados, sendo destacadas as variáveis referentes aos processos escolares. Constatações importantes resultaram de tais estudos, no que diz respeito ao desempenho escolar, à frequência às aulas e a aspectos comportamentais dos alunos (BROOKE; SOARES, 2008).

Resultados relevantes foram obtidos no estudo de Rutter et al. (1979), no qual se concluiu que o efeito das variáveis escolares de processo atuando conjuntamente apresentava-se superior quando comparado ao efeito de uma variável de processo agindo sozinha. A respeito dessa constatação, o autor aborda a escola enquanto organização social e menciona a existência de um ethos ou clima escolar que representaria a totalidade das referidas variáveis de processo atuando de forma conjunta. Assim, ganham foco os estudos cujo objeto de investigação passou a ser denominado clima escolar.

Da forma pela qual esse tema vem sendo abordado, principalmente em estudos internacionais, as percepções dos integrantes da instituição de ensino são apontadas como a melhor maneira de se traduzir elementos gerais que compõem o clima escolar (BRESSOUX, 2003). Como exemplos de aspectos investigados nesses trabalhos, podem ser citados: o conjunto de relações estabelecidas entre os integrantes da instituição de ensino; a existência de objetivos claros e aceitos por todos os membros da escola; oportunidades concedidas de participação nos assuntos escolares e a percepção que os integrantes possuem acerca da escola e a respeito da própria participação nesse espaço.

Talvez devido à abstração característica do termo clima escolar, os estudos expõem diferentes formas de defıni-lo e de operacionalizá-lo. Apesar de não haver uma defınição objetiva, os trabalhos convergem ao se referirem a uma síntese de características específicas que dão a determinada instituição uma imagem própria. Também é possível entender o conceito como processos de estabelecimento e manutenção de expectativas recíprocas entre os integrantes de uma instituição de ensino. Peterson e Skiba (2001), por exemplo, abordam o clima escolar em seu estudo, cujo tema é a violência nas instituições de ensino e o definem como os sentimentos que os alunos, e os demais integrantes da escola possuem a respeito do espaço escolar. Segundo os autores, tais sentimentos se referem às percepções individuais de bem-estar nesse ambiente, às opiniões sobre a qualidade do ensino e sobre a segurança que possuem no interior da escola.

Estudos referentes ao clima escolar são predominantemente voltados para a investigação do desempenho acadêmico dos alunos. Porém, há pesquisas que priorizam aspectos não cognitivos, principalmente os que são relacionados a fatores comportamentais. Dessa forma, além dos resultados a respeito do rendimento escolar dos alunos, há outras constatações importantes, como defendem Rutter et al. (1979). Os autores afirmam que as escolas com clima escolar positivo tendem a ter alunos e funcionários mais satisfeitos e motivados e possuem baixos índices de evasão, sendo vistas como ambientes acolhedores e seguros.

É possível citar também o estudo de Haselswerdt e Lenhardt (2003), que traz a violência escolar como tema. Os autores constataram que a maior parte dos alunos se cala diante de transgressões presenciadas na instituição de ensino, as quais são geralmente cometidas por outros alunos. Segundo os jovens, a razão para essa cumplicidade se dá pela ausência de relações de confiança entre alunos e outros membros da escola, principalmente entre alunos e professores. Dessa forma, não havendo liberdade suficiente para que os estudantes expressem suas percepções e opiniões, cria-se um clima escolar indiferente e permissivo a episódios de violência.

Com base na literatura acerca do clima escolar, os autores concluem que seria a desarticulação entre os membros da instituição de ensino o possível fator responsável pelo aumento da violência escolar, afirmação que converge com um dos principais indicadores 
de clima positivo, referente à existência de objetivos comuns entre os integrantes da escola e à articulação desses através de ações efetivas. Sob a mesma perspectiva, Juan Casassus (2007), em estudo realizado entre 1995 e 2000 em 14 países da América Latina, inclusive no Brasil, destaca a importância de haver um clima emocional adequado na escola. Tal característica é relacionada à existência de boas relações interpessoais entre todos os membros da instituição, à ausência de brigas entre alunos e de violência intraescolar. Como consequência, há também melhores resultados no que se refere ao desempenho escolar.

Quanto ao porte e uso de drogas na escola, Figueiredo et al. (2012), a partir de um estudo realizado em Diadema - município do estado de São Paulo -, verificaram que $42 \%$ das instituições se omitem em relação ao uso de drogas ilícitas entre adolescentes, principalmente naquelas que contam com classes de Educação de Jovens e Adultos (EJA). A presença do tráfico de drogas também foi constatada, sendo verificado o envolvimento de alunos de EJA em 42,9\% das escolas. Em meio a esse contexto, os autores ressaltam a importância da implementação de protocolos de orientação nas instituições, com o intuito de guiar as ações dos educadores. Para isso, os mesmos também acreditam que se torna essencial uma corresponsabilização das secretarias de saúde, bem-estar social, habitação, esporte e lazer, e segurança pública em ações conjuntas.

Alguns autores dedicam-se a investigar as relações existentes entre o uso de drogas e as circunstâncias de violência. Entretanto, é importante enfatizar a extrema complexidade dessa relação. Minayo e Deslandes (1998), por exemplo, afirmam que a influência do uso de drogas sobre situações de violência não é evidente, na medida em que é preciso esclarecer aspectos ainda obscuros, envolvendo o sentido causal entre essas substâncias e as ações de violência, principalmente no que diz respeito às influências do contexto social e das características individuais dos usuários de drogas e álcool.
Acerca das preocupações referentes à violência intraescolar e ao uso de drogas entre os jovens na instituição, Felner et al. (2001) afırmam que a existência de medidas da escola que tenham como intuito dar acesso aos estudantes a informações importantes, tais como normas escolares, expectativas e mecanismos de controle, faz com que cresça o senso de responsabilidade dos alunos e, assim, se exerça influência positiva sobre as experiências desses no que diz respeito a aspectos sociais, emocionais, comportamentais, e ao uso de substâncias químicas. De acordo com esse estudo, muitas pesquisas enfatizam a importância de se desenvolver um clima escolar positivo de forma a reduzir a violência escolar. Algumas dessas são destacadas, como os achados de Solomon et al. (2000), que ressaltam o senso de pertencimento dos estudantes à escola como o principal fator de proteção contra problemas comportamentais de alunos. Em tais estudos, destaca-se como fundamental a participação dos estudantes em questões pedagógicas de suas referidas escolas.

A partir da abordagem de estudos a respeito do clima escolar, é possível observar as semelhanças de enfoque com trabalhos referentes aos efeitos da chamada eficácia coletiva. Portanto, ao destacar tais abordagens, busca-se, na seção seguinte, salientar os pontos convergentes entre ambas e reforçar a discussão central deste estudo: a influência do clima escolar sobre percepções de violência dos alunos.

\section{Clima escolar e eficácia coletiva}

0 clima escolar é apontado como um dos fatores de influência sobre a eficácia da instituição de ensino, no que diz respeito principalmente ao desempenho escolar dos alunos, mas também em relação a aspectos comportamentais. Estudos evidenciam que, em escolas com clima escolar positivo, é marcante a coesão entre seus membros, baseada em objetivos claros, na sistematização de tais objetivos e em sua concretização. Já a eficácia 
coletiva é associada à redução do índice de criminalidade, mas, de forma similar, consiste essencialmente em relações coesas baseadas em objetivos comuns, neste caso, entre moradores de uma mesma localidade, e articulação em torno desses objetivos.

Ao analisar ambas as teorias de forma comparada, a afınidade teórica pode ser pensada a partir dos seguintes aspectos:

a) coesão social - relações de confiança e de solidariedade entre integrantes de um determinado grupo e existência de objetivos compartilhados; b) controle social informal - articulação entre integrantes de determinado grupo, visando à concretização de metas compartilhadas.

Estudos a respeito da eficácia coletiva evidenciam que a participação ativa dos moradores no que se refere à vigilância e controle do que ocorre na vizinhança - controle social informal -, quando aliada a boas relações e objetivos estabelecidos em benefício da comunidade - coesão social -, resulta na queda de indicadores de violência. No mesmo sentido, constata-se, em estudos sobre o clima escolar ,que a maior participação dos alunos, pais de alunos, professores, direção e funcionários no cotidiano da escola - forma de controle social informal - e a existência de boas relações entre esses, objetivos comuns, senso de pertencimento à escola e comprometimento em relação à instituição - coesão social - refletem -se tanto no rendimento escolar dos alunos e no trabalho desempenhado pelos funcionários em geral quanto no comportamento e atitudes dos estudantes e demais membros da instituição (FELNER et al., 2001).

A importância da coexistência de coesão e controle social informal em si já é destacada em estudos cujo tema é a eficácia coletiva e clima escolar. Exemplos referentes aos dois modelos teóricos podem ser citados. Em relação à eficácia coletiva, Browning, Feinberg e Dietz (2004) verificaram que a existência de um grupo que mantenha boas relações, as quais sejam baseadas em intenções compartilhadas, não basta para que haja uma redução na ocorrência de crimes em determinada vizinhança. Porém, quando, além de relações baseadas em objetivos comuns, em solidariedade e confiança, há a participação efetiva dos integrantes de determinado grupo em ações que visam a beneficiar sua localidade, obtêm-se resultados significativos com relação aos índices de violência. Da mesma forma, os estudos sobre clima escolar caracterizam claramente uma instituição que possui um clima escolar positivo: aquela na qual prevalecem não apenas relações de confiança e cooperação mútua mas principalmente ações baseadas em objetivos consistentes e compartilhados, e efetivas oportunidades de participação de todos os membros da comunidade escolar no cotidiano da instituição de ensino, inclusive pais ou responsáveis. A existência de boas relações por si só não caracteriza um clima escolar positivo (BROOKE; SOARES, 2008).

Ao analisarmos pontos gerais de ambas as teorias, podemos dizer que, tanto no que diz respeito aos estudos referentes ao contexto dos bairros ou comunidades quanto aos que abordam o contexto escolar, os resultados positivos relatados são comumente relacionados à eficácia das relações grupais, ou ao que se chama de eficácia coletiva no campo da sociologia urbana e de clima escolar positivo nos estudos de âmbito educacional.

Entretanto, mesmo considerando a importância e a convergência dos aspectos citados, não se pode deixar de citar a relevância de fatores intervenientes que influenciam na eficácia das relações grupais. Neste caso, trata-se das características estruturais de localidades e de seus moradores, no caso da abordagem da eficácia coletiva; e das características da escola, de seu entorno e do perfil do alunado e funcionários, em relação à perspectiva do clima escolar. Assim, quando se fala em eficácia coletiva, não se subestimam as características sociais das vizinhanças pesquisadas, sendo importante analisar conjuntamente os fatores estruturais da comunidade (SAMPSON; RAUDENBUSH; EARLS, 1997). De forma convergente, no que diz respeito aos estudos 
sobre clima escolar, além das práticas ocorridas dentro da escola, deve-se levar em consideração os aspectos extraescolares, tais como o entorno da escola e o perfil socioeconômico de seus integrantes (BROOKE; SOARES, 2008). Assim sendo, durante a análise dos dados, ambas as abordagens serão tratadas de forma articulada.

\section{Metodologia}

Os resultados analisados neste artigo são provenientes de um projeto de pesquisa mais amplo, o qual concentrou diferentes enfoques e reuniu pesquisadores de três universidades Universidade Federal do Rio de Janeiro (UFRJ), Universidade Estadual do Rio de Janeiro (UERJ) e Universidade Cândido Mendes (UCAM). Oriundo de uma das ramificações do projeto, o presente estudo tem como objetivo verificar a relação entre clima escolar e percepções de violência dos alunos, por meio da realização de um survey sobre juventude e violência em escolas municipais e estaduais, selecionadas de acordo com o perfil de seu entorno. Esta seleção foi feita a partir do levantamento das taxas de homicídios ocorridos a até $1 \mathrm{~km}$ da escola, por meio de georreferenciamento baseado em dados do ano de 2000, critério adotado de forma a possibilitar o cruzamento com os dados do censo do mesmo período.

No sistema de classificação internacional das doenças, a violência social é categorizada como causas externas, abrangendo uma longa lista de ocorrências, tais como homicídios, suicídios e acidentes em geral. Mesmo sendo considerada insuficiente diante da complexidade dos eventos de violência, avalia-se que essa classificação possibilita abordar indicadores adequados para informar e auxiliar políticas públicas (MINAYO; DESLANDES, 1998; SOUSA; NETTO, 2010). Em meio às diferentes categorias, a abordagem da taxa de homicídios neste artigo se justifica na medida em que o intuito é a seleção de áreas que tenham provavelmente maiores taxas de vitimização de jovens ${ }^{1}$, visto que um dos

1- Pesquisas recentes evidenciam que há forte associação entre violência e vitimização e a faixa-etária dos indivíduos, sendo os mais jovens, enfoques deste estudo são as percepções desses alunos sobre a violência.

Para a realização da pesquisa de campo foram inicialmente selecionadas dezesseis escolas, sendo prevista a aplicação de questionários em oito escolas municipais, especificamente para alunos do $9^{\circ}$ ano (antiga $8^{a}$ série) do ensino fundamental, e em oito escolas estaduais, do $2^{\circ}$ ano do ensino médio. Cada grupo de oito escolas foi dividido em dois, contendo quatro escolas situadas em locais com altos índices de homicídio, e mais quatro em locais com baixa incidência desse tipo de crime.

De acordo com a amostra prevista de 100 alunos por escola, responderiam aos questionários 800 alunos de instituições situadas em contexto com alta incidência de homicídios e 800 alunos em contexto com baixa incidência. Entretanto, devido a dificuldades para alcançar a meta em escolas localizadas em contextos de violência, foi obtido um total de 691 alunos nesse contexto e 822 alunos de escolas situadas em locais com baixa incidência de violência. Considerando tal diferença na amostra, os casos no banco foram ponderados para recompor a amostra prevista de 800 casos por tipo de escola. É possível que esse quadro não expresse um problema propriamente metodológico ou operacional da pesquisa.

Devido à diferença considerável do quantitativo de alunos entre os grupos de escolas citados e às observações de campo realizadas pelos pesquisadores que compareceram às escolas, supõe-se que as instituições de ensino localizadas em áreas de maior violência tenham realmente menos alunos, devido ao contexto mais violento. Entretanto, de modo a testar tal suposição, seriam necessárias investigações complementares, as quais ultrapassam o escopo deste artigo.

No que diz respeito à operacionalização das análises, além da relação entre variáveis de clima escolar e variáveis de percepção de violência na escola, será verificada a relação entre clima escolar e existência de drogas e

aproximadamente entre 15 e 24 anos de idade, os mais propensos à prática de crimes e os mais vulneráveis à vitimização. 
bebidas alcoólicas na instituição. Portanto, será abordada uma variável referente a drogas e bebidas alcoólicas, de forma a verificar uma possível associação com contextos de violência e analisar o modo como essa variável se relaciona com os indicadores de clima escolar. A seguir, serão especificadas as variáveis utilizadas.

\section{Variáveis dependentes}

\section{a) Violência intraescolar}

Testemunhos dos estudantes sobre situações envolvendo brigas e agressões físicas entre alunos. Nesse caso, vale destacar que as brigas se referem tanto a agressões verbais quanto a agressões físicas, visto que os dois tipos de agressão citados costumam ser imbricados em determinadas circunstâncias. Os testemunhos foram obtidos através de uma questão do survey que pede aos alunos que sinalizem a frequência com a qual observaram, ao longo dos 12 meses antecedentes, situações de brigas e agressões físicas.

\section{b) Alunos com drogas e bebidas alcoólicas na escola}

Esta variável se refere às respostas dos alunos sobre a frequência com a qual viram outros estudantes portando drogas ou bebidas alcoólicas na escola. No questionário, trata-se de uma pergunta que pede para que o aluno assinale a frequência com que determinadas situações ocorreram na escola ao longo dos 12 meses precedentes, sendo cada item uma circunstância diferente, entre eles: "alunos com bebidas alcoólicas" e "alunos com drogas como maconha ou cocaína". As respostas para os dois itens foram somadas, dando origem à variável "alunos com drogas e bebidas alcoólicas na escola”. É importante enfatizar que, durante a aplicação do questionário, a qual foi orientada por dois pesquisadores, os alunos foram informados de que poderiam considerar outras drogas, além de maconha e cocaína, sendo a menção das referidas somente para fins ilustrativos. Dessa forma, tam- bém seriam considerados outros tipos de drogas, como solventes, drogas sintéticas e o crack.

\section{c) Alunos com armas na escola}

Esta variável foi construída a partir da junção de dois itens da pergunta do questionário sobre a frequência de determinadas situações na escola, a qual foi citada nos tópicos anteriores. Os itens referentes ao porte de armas são: "alunos portando armas de fogo" e "alunos com outras armas: facas, canivetes etc.”.

\section{Variáveis independentes}

\section{a) Indicadores de clima escolar}

- Variável referente à avaliação dos alunos sobre diferentes dimensões escolares: organização; segurança; professores; direção/ coordenação; funcionários em geral; qualidade do ensino; limpeza; beleza; merenda/refeição;

- Percepções sobre como os alunos se sentem na instituição (escala de cinco opções de resposta: muito bem; bem; mais ou menos; mal; muito mal);

- Visão geral que os alunos possuem a respeito da escola, comparada a outras da região (escala de cinco opções de resposta: muito melhor que as outras; melhor que as outras; igual às outras; pior que as outras; muito pior que as outras).

b) Número de homicídios no entorno da escola: registro de homicídios a até 300 metros da escola, realizado por meio de georreferenciamento ${ }^{2}$.

c) Exposição à violência: situações de violência presenciadas pelos jovens.

d) Abordagem policial: experiências que envolvem a presença de policiais.

e) Experiências de violência: situações envolvendo agressão física e/ou ameaças com faca ou arma de fogo.

2- Para a seleção das escolas deste estudo, foi estabelecido o registro de ocorrência de homicídios a até $1 \mathrm{~km}$ da escola; já neste caso, verifica-se a ocorrência a até $300 \mathrm{~m}$, com 0 intuito de verificar as escolas situadas em áreas ainda mais violentas. 


\section{Variáveis de controle}

a) Dados sociodemográficos:

- cor

- sexo

- idade

Apesar de declaradas, o preenchimento das respostas referentes à cor foi conferido pelos pesquisadores no momento da entrega, o que resultou em percentual consideravelmente baixo de não respostas. 0 mesmo ocorreu em relação às respostas relativas a sexo e idade.

b) Nivel socioeconômico: soma dos bens e número de moradores por dormitório.

c) Composição domiciliar: lares monoparentais, compostos somente por um dos pais do aluno.

\section{Análise dos resultados}

É importante esclarecer que, além da verificação de percepções acerca do clima escolar, as análises realizadas neste estudo correspondem às percepções dos jovens sobre circunstâncias de violência e uso de drogas na escola e não ao levantamento de ocorrências concretas. Dessa forma, assim como destacam Souza e Souza (2010), vale enfatizar que não são apenas os acontecimentos violentos que afetam as percepções dos alunos sobre a violência existente; essas também podem ser afetadas por notícias sobre casos de violência ou quando se é vítima de atos violentos, sendo o medo fator responsável por influenciar comportamentos e ações, e por intensificar a sensação de exposição à violência.

\section{Análises descritivas}

As primeiras análises realizadas buscaram investigar a relação entre percepções dos alunos a respeito de ocorrências de violência, porte de drogas e armas na instituição de ensino e a avaliação dos mesmos sobre suas escolas, quando comparadas a outras da região. Supõe-se que tal comparação pode ser realizada em relação às demais instituições existentes no mesmo bairro ou em bairros vizinhos, as quais possam ser conhecidas pelos jovens.

A tabela abaixo cruza as percepções dos alunos sobre violência, drogas e armas na instituição e a avaliação dos mesmos sobre suas escolas em relação a outras da região. Por exemplo, dentre os alunos que opinaram a respeito da existência de violência, drogas e armas na instituição de ensino, verifica-se também como esses avaliam suas escolas em relação às outras. Análises desse tipo são realizadas por meio de tabelas de contingência, as quais permitem observar a relação entre duas ou mais variáveis, normalmente de escala nominal.

A seguir, são destacadas as variáveis que compõem a tabela abaixo.

Tabela 1 - Percepções dos alunos sobre violência intraescolar, porte de armas e drogas na escola, de acordo com a visão geral que possuem a respeito da instituição ${ }^{3}$

\begin{tabular}{|c|c|c|c|c|}
\hline & $\begin{array}{l}\text { Brigas e agressões físicas } \\
\text { entre alunos }\end{array}$ & $\begin{array}{l}\text { Alunos com armas de } \\
\text { fogo na escola }\end{array}$ & $\begin{array}{l}\text { Alunos com outras armas } \\
\text { (facas, canivetes etc.) }\end{array}$ & $\begin{array}{c}\text { Alunos com drogas/ } \\
\text { bebidas na escola }\end{array}$ \\
\hline Muito melhor que as outras & $59 \%$ & $2 \%$ & $9 \%$ & $16 \%$ \\
\hline Melhor que as outras & $62 \%$ & $1 \%$ & $13 \%$ & $15 \%$ \\
\hline Igual às outras & $56 \%$ & $2 \%$ & $12 \%$ & $10 \%$ \\
\hline Pior que as outras & $55 \%$ & $3 \%$ & $15 \%$ & $14 \%$ \\
\hline Muito pior que as outras & $76 \%$ & $13 \%$ & $28 \%$ & $41 \%$ \\
\hline
\end{tabular}

Fonte: Dados da pesquisa

3- Os alunos puderam citar mais de uma situação de violência, porte de armas e drogas. Por isso, os valores ultrapassam os 100\%. 
- Situações de violência: "brigas e agressões físicas entre alunos";

- Armas na escola: "alunos com armas de fogo na escola", "alunos com outras armas (facas, canivetes etc.)";

- Drogas na escola: "alunos com drogas/ bebidas alcoólicas na escola”;

- Avaliação dos alunos sobre as escolas, comparadas a outras da região: "muito melhor que as outras", "melhor que as outras", "igual às outras”, "pior que as outras”, "muito pior que as outras".

A partir da tabela acima, na segunda coluna, é possível observar altos percentuais de alunos que já presenciaram circunstâncias de brigas e agressões físicas em suas escolas, independentemente da forma como esses as avaliam. Entretanto, destacam-se os alunos que consideram suas respectivas escolas como muito piores que as outras, na medida em que 76\% desses afirmam existir brigas e agressões na escola. Em relação ao testemunho dos alunos sobre armas de fogo nas instituições, os dados seguem a mesma tendência, já que 13\% dos estudantes que presenciaram tal circunstância avaliam suas escolas como muito piores que as outras, percentual que se destaca dos demais. 0 mesmo ocorre quando se trata de outras armas, visto que $28 \%$ dos alunos que já testemunharam estudantes com outras armas avaliam suas escolas como muito piores. Por fim, quanto às percepções sobre ocorrências de alunos com drogas na escola, observa-se novamente a avaliação da instituição como muito pior que as outras sendo o diferencial, na medida em que $41 \%$ dos alunos que afirmam terem visto alunos com drogas/bebidas na escola avaliam suas escolas dessa forma.

Assim, esses dados apontam para uma possível associação entre escolas muito mal avaliadas pelos alunos, que seria um indicador de clima escolar negativo, e um ambiente mais propício à violência. A constatação dessa associação é consonante aos estudos que mostram a relação entre incidência de circunstâncias de violência dentro da escola e as dificuldades de se estabelecer um clima escolar propício à aprendizagem. (RUTTER et al. 1979; SOLOMON et al., 2000; FELNER et al. 2001; PETERSON; SKIBA, 2001; HASELSWERDT; LENHARDT, 2003, CASASSUS, 2007). A existência de drogas e armas na escola mostra também uma provável falha na supervisão e controle, seja da escola ou de órgãos superiores responsáveis pela manutenção de um ambiente seguro para alunos e funcionários em geral.

\section{Correlações: aspectos escolares e} experiências de violência

Abaixo são apresentadas correlações entre variáveis referentes a percepções de violência dos alunos e percepções sobre aspectos gerais de suas escolas.

A correlação positiva verificada entre a incidência de alunos com drogas e bebidas alcoólicas na escola e a violência intraescolar, com coeficiente igual a 0,5, considerado moderado, permite-nos supor uma associação entre essas duas situações no espaço escolar.

É possivel verificar também que todas as variáveis de percepções de violência extraescolar estão positivamente correlacionadas às percepções de violência intraescolar, e ambas estão negativamente correlacionadas à variável de avaliação geral da escola, um dos indicadores de clima escolar. Por suposição, esse dado pode ser interpretado como a existência de direções equivalentes entre as percepções de violência dentro e fora da escola, ou seja, alunos que relataram ocorrências de violência dentro da escola também tendem a relatar ocorrências de violência fora da escola e vice-versa. No que se refere à satisfação dos alunos com a instituição de ensino e percepções de violência dentro e fora da escola e de drogas dentro da escola, verificam-se também direções opostas, ou seja, nas instituições em que muitos alunos já testemunharam ocorrências de violência e drogas, a avaliação geral da escola tende a ser negativa. 
Tabela 2 - Aspectos escolares e experiências de violência

\begin{tabular}{|c|c|c|c|c|c|c|}
\hline & $\begin{array}{c}\text { Violência } \\
\text { intraescolar }\end{array}$ & $\begin{array}{c}\text { Alunos com } \\
\text { bebidas/drogas }\end{array}$ & $\begin{array}{l}\text { Avaliação geral } \\
\text { da escola }\end{array}$ & $\begin{array}{l}\text { Exposição à } \\
\text { violência }\end{array}$ & $\begin{array}{l}\text { Abordagem } \\
\text { policial }\end{array}$ & $\begin{array}{l}\text { Experiência } \\
\text { de violência }\end{array}$ \\
\hline Violência intraescolar & 1 &, $500^{\star *}$ &,$- 084^{* *}$ &, $142^{* *}$ &, $154^{\star *}$ &, $250^{\star *}$ \\
\hline Alunos com bebidas/drogas &, $500^{\star *}$ & 1 &,$- 108^{\star *}$ &, $158^{\star \star}$ &, $111^{\star *}$ &, $142^{\star *}$ \\
\hline Avaliação geral da escola &,$- 084^{\star \star}$ &,$- 108^{\star \star}$ & 1 &,- 009 &,$- 054^{*}$ &,$- 064^{*}$ \\
\hline Exposição à violência &, $142^{\star \star}$ &, $158^{\star \star}$ &,- 009 & 1 &, $476^{\star *}$ &, $164^{\star \star}$ \\
\hline Abordagem policial &, $154^{\star *}$ &, $111^{\star *}$ &,$- 054^{*}$ &, $476^{\star \star}$ & 1 &, $214^{\star \star}$ \\
\hline Experiência de violência & 250 ** &, $142^{\star \star}$ &,$- 064^{*}$ & $164^{* *}$ &, $214^{\star \star}$ & 1 \\
\hline
\end{tabular}

${ }^{\star *} p<0,001{ }^{*} p<0,05$

Fonte: Dados da pesquisa

Certamente, há fatores que são intervenientes aos observados e que podem contribuir para a explicação das referidas relações. 0 objetivo da próxima seção é justamente aprofundar esta investigação por meio de análises multivariadas, levando em conta outros fatores que podem exercer influência sobre os resultados.

\section{Regressões lineares: violência} intraescolar, alunos com drogas e bebidas alcoólicas na escola e percepções sobre a instituição de ensino

Tendo como variável dependente as percepções dos alunos sobre violência intraescolar, dentre as variáveis significativas do modelo, destacam-se: os coeficientes positivos de alunos com drogas e bebidas alcoólicas na escola, igual a 0,524; abordagem policial, igual a 0,075; e experiências de violência, igual a 0,120. Com o coeficiente mais alto do modelo, sobressai-se a variável referente a alunos com drogas e bebidas alcoólicas na escola, dado que indica a associação positiva dessa variável às percepções de violência intraescolar, confirmando a tendência verificada nas análises anteriores. Também é possível supor associações entre percepções de violência intraescolar e percepções de violência extraescolar, no caso dos coeficientes positivos relativos a "experiências de violência" e "abordagem policial”. Essa tendência é igualmente verificada na matriz de correlações precedente. Considerando esses resultados, pretende-se, na regressão seguinte, verificar quais fatores relacionam-se à variável referente a alunos com drogas e bebidas alcoólicas na escola.

Tabela 3 - Regressão linear para percepções de violência intraescolar

\begin{tabular}{l:c}
\hline Cor (negros) & ,034 \\
\hline Sexo (masculino) & ,043 \\
\hline Idade (maior faixa etária) &,- 030 \\
\hline Nível socioeconômico &,- 016 \\
\hline Lares monoparentais &,- 024 \\
\hline $\mathrm{N}^{\circ}$ de homicídios a 300 metros da escola &,- 016 \\
\hline Avaliação geral da escola &, 005 \\
\hline Alunos com drogas e bebidas alcoólicas &, $524^{\star \star}$ \\
\hline Exposição à violência &, 000 \\
\hline Abordagem policial &, $075^{\star}$ \\
\hline Experiências de violência &, $120^{\star \star}$ \\
\hline
\end{tabular}

Variável dependente: Violência intraescolar - ${ }^{* \star} p<0,001{ }^{*} p<0,05$ - R2 ajustado: 0,33

Coeficientes de regressão padronizados (Beta)

Fonte: Dados da pesquisa

Antes disso, vale destacar alguns resultados, mesmo que não sejam significativos, isso porque, em determinados casos, a direção dos coeficientes é convergente ao que se afirma pela literatura e, em outros, há resultados interessantes que valem ser mencionados. A começar pelos coeficientes positivos das variáveis referentes à cor e ao sexo, iguais a 0,34 e a 0,43 , os quais indicam que jovens negros e do sexo masculino são os que mais relatam situações de violência, verifica-se que 
são consonantes à literatura, a qual evidencia maior envolvimento de jovens do sexo masculino e negros em contextos de violência (BEATO, 2000; ZALUAR; LEAL, 2001; SOARES; CANO, 2002, RAMOS; LEMGRUBER, 2004). Vale destacar também o coeficiente relativo ao nível socioeconômico (NSE), igual a $-0,16$, que significa que alunos de NSE mais alto relatam menos situações de violência intraescolar, e vice-versa. Uma suposição que pode ser feita nesse sentido é o fato de alunos com maior NSE estudarem em escolas que possuem menor incidência de violência intraescolar. Outra hipótese é a possibilidade de alunos com esse perfil estudarem em escolas localizadas em áreas menos violentas, de forma que sofrem menor influência do contexto externo. Mas essas são somente suposições.

0 coeficiente de $-0,016$, referente ao número de homicídios a até 300 metros da escola, também chama a atenção, na medida em que indica que quanto maior é o número de homicídios no entorno da escola menor é percepção de violência intraescolar. Em primeiro lugar, é preciso destacar que esse dado não se refere a percepções, já que o número de homicídios foi obtido através de georreferenciamento. De acordo com o que se espera, esse resultado deveria estar justamente na direção oposta, considerando a provável influência do contexto externo sobre o interno. Entretanto, como se trata de percepções, é possível que alunos de escolas localizadas em áreas mais violentas, por circularem nelas com maior frequência, tendam a naturalizar algumas circunstâncias que são vistas como mais graves por jovens que estejam menos expostos a tais contextos.

Outra hipótese é a existência de ações mais enérgicas e efetivas por parte da equipe pedagógica de tais escolas, de supervisão e controle, devido ao contexto de extrema violência externa. Outro resultado intrigante é o coeficiente positivo, igual a 0,005 , referente à avaliação da escola, o qual indica que, quanto mais satisfeitos com a escola, maiores são também as percepções de violência intraescolar, resultado oposto ao evidenciado pela literatura, e contrário também às análises realizadas até então. Contudo, esse possui um dos mais baixos coeficientes da regressão, além de não ser significativo, assim como os demais mencionados anteriormente. Parte dos dados não significativos foi destacada com o intuito de prestar esclarecimentos, e pelo fato de alguns apresentarem resultados interessantes. Entretanto, por não serem significativos, seus resultados não podem ser considerados para a realização de associações e inferências.

Tabela 4 - Regressão linear para percepções sobre alunos com drogas e bebidas alcoólicas

\begin{tabular}{l:c}
\hline Cor (negros) &,- 011 \\
\hline Sexo (masculino) &,- 033 \\
\hline Idade (maior faixa etária) &, $058^{\star}$ \\
\hline Nível socioeconômico &,- 002 \\
\hline Lares monoparentais &, 018 \\
\hline$N^{\circ}$ de homicídios a 300 metros da escola &,- 041 \\
\hline Avaliação geral da escola &,$- 092^{\star *}$ \\
\hline Violência intraescolar &, $526^{\star \star}$ \\
\hline Abordagem policial &,- 014 \\
\hline Experiências de violência &, $060^{\star}$ \\
\hline Exposição à violência &, $101^{\star *}$ \\
\hline
\end{tabular}

Variável dependente: alunos com drogas e bebidas alcoólicas na escola ${ }^{* *} p<0,001{ }^{*} p<0,05-$ R2 ajustado: 0,32 - Coeficientes de regressão padronizados (Beta)

Fonte: Dados da pesquisa

A idade é o primeiro coeficiente significativo observado no modelo, o que significa dizer que a percepção sobre alunos com drogas e bebidas alcoólicas pode ser mais frequente entre os estudantes de maior faixa etária. Uma hipótese possível seria a maior exposição desses jovens a circunstâncias de uso de drogas e de consumo de bebidas alcoólicas. De forma convergente, Figueiredo et al. (2012), como citado na revisão bibliográfica, apontam o uso de drogas entre jovens de maior faixa etária, que no caso são alunos de classes de Educação de Jovens e Adultos (EJA), sendo constatado também maior envolvimento desses com o tráfico de drogas. 
A variável relativa à violência intraescolar possui o coeficiente mais alto do modelo, o que ratifica os resultados das análises anteriores, no que diz respeito à associação entre percepção de violência dentro da escola e percepção sobre a existência de alunos com drogas e bebidas alcoólicas na instituição. As variáveis de experiências de violência e exposição à violência também se mostram significativas e com sinal positivo, o que significa dizer que alunos que relatam a existência de drogas e bebidas alcoólicas na escola também tendem a relatar ocorrências de violência em geral, que podem ser dentro e/ou fora da escola. Esse dado confirma os resultados mostrados até aqui.

Assim como evidenciado nas análises descritivas e nas correlações, é possível verificar, nessa última regressão, uma associação negativa entre a percepção dos alunos sobre a existência de drogas e bebidas alcoólicas na escola e a avaliação deles acerca de aspectos gerais da instituição. Isto é, quanto maior é a percepção referente à existência de alunos com drogas e bebidas alcoólicas nas escolas, menos bem avaliadas são essas instituições. Alguns estudos chegam às mesmas constatações a respeito das implicações negativas da existência de drogas e violência dentro da escola em relação à organização e coesão interna da instituição, à satisfação dos alunos e funcionários com a escola, ao estabelecimento de um clima escolar propício à aprendizagem e, consequentemente, ao desempenho escolar dos alunos (PETERSON; SKIBA, 2001; HASELSWERDT; LENHARDT, 2003; CASASSUS, 2007).

Um dos resultados destacados na análise dos dados diz respeito à convergência entre as percepções de violência dos alunos sobre o contexto intra e extraescolar, dado que é de certa forma esperado, visto que o contexto social no qual a escola está inserida exerce influência sobre suas dinâmicas internas. Alguns autores abordam as dificuldades que escolas situadas em localidades com altas incidências de violência possuem para evitar que tais ocorrências sejam frequentes também no espaço escolar. Apesar de não abordar propriamente conceitos como o de eficácia coletiva e clima escolar, Zaluar e Leal (2001) destacam a importância de um mínimo de consenso interno para que a instituição escolar resista ao cerco da violência.

Nesse sentido, é importante destacar a relevância de uma atuação conjunta entre escola e comunidade externa. Um exemplo que pode ser citado é o estudo de Felner et al. (2001). Ao investigar os aspectos associados ao clima escolar, os autores ressaltam a relação entre a escola e a comunidade como um dos fatores essenciais para o estabelecimento de um clima escolar positivo. Articulando a teoria referente à eficácia coletiva (SAMPSON; RAUDENBUSH; EARLS, 1997) a essa perspectiva, pode ser pensado o estabelecimento de um diálogo entre a escola e as localidades de seu entorno, de forma a buscar ações conjuntas para combater ocorrências de violência envolvendo os jovens, tornando tais ações complementares e mais consistentes.

0 estudo de Souza e Souza (2010) evidencia ações que se assemelham a essa perspectiva, mas que ultrapassam os domínios da escola. Realizada em Belo Horizonte, a pesquisa reúne ações de mobilização e articulação de grupos de diversas áreas - educação, saúde, esportes, cultura, assistência social, associações e moradores da comunidade -, visando a contribuir para a prevenção à criminalidade de forma mais sistemática. Dentre as etapas do projeto, após diagnóstico a respeito de como as escolas lidam com a violência, os gestores das instituições de ensino, representantes de cada área de atuação social citada acima e líderes comunitários se reúnem para momentos de discussão e planejamento de ações conjuntas, construídas coletivamente.

A respeito da convergência verificada entre percepções de violência intraescolar e a incidência de alunos com drogas e bebidas alcoólicas, Solomon et al. (2000) mostram a importância de se estimular a participação dos jovens em dinâmicas escolares diversas, promovendo assim o senso de pertencimento dos alunos à escola e de responsabilidade sobre suas ações, o que tem como consequência 
também a queda nas ocorrências de indisciplina e de violência nas escolas.

Também é possível destacar a importância das constatações de Sampson, Raudenbush e Earls (1997), pioneiros nos estudos a respeito da eficácia coletiva. Entre seus achados, os autores apontaram a supervisão e o controle dos grupos de adolescentes como indicador mais significativo para o combate das ocorrências de violência. No mesmo sentido, Shaw e McKay (1942) já abordavam, na década de 1940, o envolvimento de jovens em circunstâncias de violência como fenômeno de grupo, resultante de frágeis e ineficientes meios de supervisão e controle. Esses autores falam principalmente de controle e supervisão e fatores relacionados ao grau de coesão da comunidade. Com perspectiva similar, alguns estudos na área da educação constatam que a coesão interna e ações baseadas em objetivos compartilhados são fatores importantes para que haja um bom clima escolar.

\section{Considerações finais}

0 esforço teórico deste estudo, ao articular as teorias referentes à eficácia coletiva e ao clima escolar, teve por objetivo investigar os processos intraescolares, as circunstâncias de violência que os perpassam e suas implicações, além de pretender suscitar questões para a realização de estudos subsequentes.

É possível atribuir um caráter exploratório aos resultados e às articulações teóricas realizadas, devido à escassez de abordagens que relacionem as contribuições das duas linhas teóricas em questão. Apesar de haver estudos acerca das percepções de alunos a respeito da violência nas escolas, são escassos também enfoques que articulem a essa questão evidências sobre o clima escolar.

A partir dos resultados evidenciados, podemos pensar em estudos subsequentes que explorem as relações mostradas e questões relacionadas, tais como: (1) relação entre clima escolar, violência e suas implicações para o desempenho escolar dos alunos; (2) influência da participação dos pais/responsáveis no cotidiano escolar sobre as percepções dos alunos a respeito da violência intraescolar; e (3) impacto das UPPs (Unidades de Polícia Pacificadoras), no caso do município do Rio de Janeiro, sobre as percepções dos alunos acerca da violência intraescolar.

\section{Referências}

BEATO, Cláudio. Determining factors of criminality in Minas Gerais. Review of Social Sciences, n. 1, out., 2000. Special issue.

BRESSOUX, Pascal. As pesquisas sobre o efeito-escola e o efeito-professor. Educação em Revista, Belo Horizonte, n. 38, dez. 2003. BROOKE, Nigel; SOARES, José Francisco. Pesquisa em eficácia escolar: origem e trajetórias. Belo Horizonte: Ed. UFMG, 2008. BROWNING, Christopher R.; FEINBERG, Seth L.; DIETZ, Robert D. The paradox of social organization: networks, collective efficacy, and violent crime in urban neighborhoods. Social Forces, v. 83, n. 2, p. 503-534, dec. 2004.

CANO, Ignacio; SOARES, G. D. As teorias sobre as causas da criminalidade. Rio de Janeiro: IPEA: Manuscrito, 2002.

CASASSUS, Juan. A escola e a desigualdade. Unesco, 2007.

FELNER, Robert et al. Whole school improvement and restructuring as prevention and promotion: lessons from project STEP and the project on high performance learning communities. Journal of School Psychology, v. 39, n. 2, p. 17-202, mar-apr. 2001. 
FIGUEIREDO, Regina; et al. Ocorrência de violência e drogas envolvendo alunos de escolas municipais de Diadema - São Paulo. Revista do Laboratório de Estudos da Violência e segurança da UNESP, Marília, n. 10, dez. 2012.

HASELSWERDT, Michael V.; LENHARDT, Ann Marie C. Reframing school violence: listening to voices of students. The Educational Forum, v. 67, 2003.

MINAYO, Maria Cecília; DESLANDES, Suely F. Cadernos de Saúde Pública. Rio de Janeiro, jan-mar., 1998.

PETERSON, Reese L.; SKIBA, Russel. Creating school climates that prevent school violence. The Social Studies, v. 74, n. 3, p. 155-163, jan-feb. 2001.

RAMOS, Silvia, LEMGRUBER, Julita. Criminalidade e respostas brasileiras à violência. Observatório da Cidadania, p. 45-52, 2004.

RUTTER, Michael et al. Fifteen thousand hours: secondary schools and their effects on children. In: BROOKE, Nigel; SOARES, José Francisco (Orgs.). Pesquisa em eficácia escolar: origem e trajetórias. Belo Horizonte: Ed. UFMG, 2008.

SAMPSON, Robert J., RAUDENBUSH, Stephen W., EARLS, Felton. Neighborhoods and violent crime: a multilevel study of collective efficacy. Science, v. 277, n. 5328, p. 918-924, 15 aug. 1997.

SILVA, Bráulio Figueiredo Alves da. Coesão social, desordem percebida e vitimização em Belo Horizonte. 2004.80 f. Dissertação (Mestrado em Sociologia) - Faculdade de Filosofia e Ciências Humanas, Universidade Federal de Minas Gerais, Belo Horizonte, 2004.

SOLOMON, Daniel et al. A six-district study of educational change: direct and mediated effects of the child development project. Social Psychology of Education, v. 4, p. 3-51, 2000.

SOUSA, Selonia Patrícia 0.; SOUSA NETTO, Otacílio Batista. Acidentes e violências causam 700 mil internações e gasto de R\$ 900 milhões. Observatório Epidemológico; Teresina, ano13, ed. 29, 2010.

SOUZA, Robson S. R.; SOUZA, Ângela Maria D. N. Juventude e violência: novas demandas para a educação e a segurança públicas. Revista Brasileira de Segurança Pública, n. 6, fev-mar. 2010.

ZALUAR, Alba; LEAL, Maria Cristina. Violência extra e intramuros. Revista Brasileira de Ciências Sociais, v. 16, n. 45, fev. 2001. Disponível em: <http://www.scielo.br/pdf/rbcsoc/v16n45/4335.pdf>. Acesso em: 12 jan. 2014.

Recebido em: 26.12.2012

Aprovado em: 16.10 .2013

Marcela Brandão Cunha possui graduação em Pedagogia pela Universidade Federal do Rio de Janeiro (2007) e mestrado em Educação pela mesma universidade (2010). Atualmente é doutoranda em Educação pela Pontifícia Universidade Católica do Rio de Janeiro. 